\title{
Triacylglycerols in the rat uterine epithelium during the oestrous cycle and early pregnancy
}

\author{
D. P. Boshier, Hilary Holloway and Ngaire M. Millener \\ Anatomy Department, School of Medicine, University of Auckland, Auckland, New Zealand
}

\begin{abstract}
Summary. Specific histochemical techniques showed triacylglycerols to be the predominant neutral lipid in intracellular lipid droplets of uterine epithelial cells. After their extraction from pure samples of uterine epithelial cells, triacylglycerols were in lower concentration $(\mu \mathrm{g} / \mu \mathrm{g}$ DNA) during pro-oestrus $(0.4)$ than at any other stage of the oestrous cycle $(0.73-0.86)$, decreased during Days $3(0.5), 4(0.25)$ and $5(0.24)$ of pregnancy, and were lower in ovariectomized females receiving oestradiol $(0.18)$ than in those receiving medroxyprogesterone acetate $(0.93)$. It is suggested that these triacylglycerols could be used by the blastocysts and their contiguous endometrium as a readily available energy and metabolite source during implantation.
\end{abstract}

\section{Introduction}

The intracellular droplets that can be visualized by using fat-soluble dyes (e.g. oil red $\mathrm{O}$ ) have been shown in the kidney tubular epithelium to contain neutral lipids (Nissen \& Bojesen, 1969). The main components of these neutral lipids are triacylglycerols, compounds in which three fatty acids, or acyl radicals, are linked through ester groups to the glycerol backbone. After esterase activity, the fatty acids may be used catabolically as constituents of other lipids or anabolically as energy sources following $\beta$ oxidation.

Variations in the neutral lipid levels in the rat uterine epithelium correlate with the reproductive state of the female (Alden, 1947; Boshier \& Holloway, 1973) and depend on the periodic stimulation of the epithelial esterases by cyclic increases in the concentration of plasma oestrogens (Boshier \& Katz, 1975). Further, at the site of blastocyst implantation, whilst the neutral lipids disappear from the epithelium surrounding the blastocyst, they remain in the epithelium outside the implantation site and may be present within the blastocysts itself (Boshier, 1976). Such findings are highly suggestive of a specific localized role for uterine epithelial triacylglycerols as an energy source and a source of useful metabolites. The fatty acid components may be used as precursors of prostaglandins (Bojesen, 1974), which are now known to be of importance in the implantation process of a number of species (Kennedy \& Zamecnik, 1978).

Because these putative roles are consistent with the above and other observations (Alden, 1947; Beall \& Werthessen, 1971; Kennedy, 1977) and because previous histochemical studies have been qualitatively and quantitatively non-specific, we undertook specific histochemical and biochemical investigations of the relationship between ovarian hormones and the neutral lipids, particularly the triacylglycerols, of the rat uterine epithelium during the oestrous cycle and early pregnancy.

Parts of this work have been reported previously (Boshier \& Millener, 1980). 


\section{Materials and Methods}

\section{Animals and treatment}

The Charles River Wistar rats used were young but mature females from the Auckland Medical School's SPF Rat Reproduction Unit where they were housed under standard conditions $\left(12 \mathrm{~h}\right.$ light $/ 24 \mathrm{~h} ; 21 \pm 2^{\circ} \mathrm{C}$ ) with rat pellets (Westfield diet 86 ) and water freely available. Entire females were used experimentally only after the completion of two normal oestrous cycles and for ovariectomized females confirmatory vaginal smears were taken post-operatively for 1 week. For the studies of pregnant uteri, females were mated with males of proven fertility and the morning of finding vaginal spermatozoa was designated Day 1 of pregnancy.

The ovariectomized females were treated, 14 or more days post-operatively, with a subcutaneous injection of $0.1 \mu \mathrm{g}$ oestradiol benzoate (Paines \& Byrne) in $0.2 \mathrm{ml}$ arachis oil on 7 consecutive days, or a single injection of $2.0 \mathrm{mg}$ medroxyprogesterone acetate (MPA: Upjohn). Both groups of females were killed 7 days after the first injection.

\section{Histochemistry}

Following detailed studies of the validity of the major methods for staining intracellular lipids, Bayliss High (1977) recorded the most specific techniques for distinguishing between the various lipid classes. Her modifications of the techniques for triacylglycerols (calcium lipase method), free fatty acids (calcium lipase method), cholesterol esters (perchloric acidnaphthoquinone method), and free cholesterol (digitonin/perchloric acid-naphthoquinone method) have been followed in this study, using in each case chloroform-methanol-extracted control sections. Liquid hydrophobic neutral lipids were stained with oil red $O$ as previously described (Boshier, 1976).

Following fixation for at least $48 \mathrm{~h}$ in calcium-formol at $4^{\circ} \mathrm{C}$, thin sections $(6-8 \mu \mathrm{m})$ of metoestrous rat uteri were cut in a microtome cryostat at $-30^{\circ} \mathrm{C}$ and stained by one of the above methods. At least 14 sections were stained for the study of each lipid class, each section being examined visually and scored as positive or negative for the presence of the particular lipid sought.

\section{Extraction of triacylglycerols}

Pure samples of uterine epithelial cells were obtained as described previously (Boshier \& Katz, 1975), except for the pregnant and progestagen-treated ovariectomized females. For these, the uterine horns were inverted onto the rods normally used and hand shaken in a tube containing $\mathrm{Ca}^{2+}$ - and $\mathrm{Mg}^{2+}$-free Hanks solution at $37^{\circ} \mathrm{C}$, whereupon the epithelium became detached as sheets of cells. Epithelial cells from 3-6 females were combined for later biochemical analysis.

After centrifugation $(400 \mathrm{~g})$, the cell pellet was washed with Dulbecco's phosphate-buffered saline $\left(\mathrm{pH} 7.3,37^{\circ} \mathrm{C}\right)$, weighed, resuspended in 30 volumes of chloroform : methanol $(1: 1 \mathrm{v} / \mathrm{v})$ and allowed to stand for $1 \mathrm{~h}$ at $20^{\circ} \mathrm{C}$. The cells were re-centrifuged and the pellet homogenized (Tri-R Instruments Inc., New York) using a ground-glass pestle in 20 volumes of chloroform:methanol $(2: 1 \mathrm{v} / \mathrm{v})$ in ice (Folch, Lees \& Sloane Stanley, 1957). After further centrifugation, the cell residue was re-extracted twice with 20 volumes of the same solvent mixture.

The combined supernatants were evaporated under $\mathrm{O}_{2}$-free $\mathrm{N}_{2}$ and the methanol was removed by the addition and evaporation of small aliquots of chloroform. Final extracts were re-dissolved in chloroform containing $0.005 \%$ butylated hydroxytoluene as antioxidant and stored under $\mathrm{N}_{2}$ at $-20^{\circ} \mathrm{C}$. 
The residue, dried under $\mathrm{N}_{2}$, was then washed with ethanol and the DNA extracted at $90^{\circ} \mathrm{C}$ with $5 \%$ trichloracetic acid for $15 \mathrm{~min}$. After centrifugation, an aliquot of supernatant was assayed for DNA by the method of Burton (1956), except that only one volume of diphenylamine reagent was used in order to increase the assay sensitivity.

Each final lipid extract was then fractionated by thin layer chromatography on pre-washed $20 \times 20 \mathrm{~cm}$ silica gel plates (G, Merck), using the solvent system diethyl ether:glacial acetic acid : petroleum ether (100:3:97 by vol.) run to $9 \mathrm{~cm}$ above the origin, with re-development in diethyl ether:petroleum ether $(3: 97 \mathrm{v} / \mathrm{v})$ run to $16 \mathrm{~cm}$ above the origin (Hojnacki \& Smith, 1974). The lipid standard contained reference monoglyceride (monostearin; Sigma), diglyceride (dipalmitin; Sigma), triglyceride (tripalmitin; Sigma), cholesterol (Sigma), and cholesterol ester (cholesterol palmitate; Sigma).

\section{Triacylglycerol assay}

After lipid visualization by brief exposure of the plate to $I_{2}$ vapour, the appropriate portions of silica gel were scraped from the plate into vials and the associated triacylglycerols eluted with 3 washes of $2 \mathrm{ml}$ chloroform:methanol:diethyl ether (1:1:1 by vol.). The solvent was then evaporated under nitrogen and the triacylglycerols assayed by the method of Galetti (1967), using tripalmitin as standard. Results were expressed as $\mu \mathrm{g}$ triacylglycerol/ $\mu \mathrm{g}$ DNA.

Standard statistical techniques for analysis of variance were used, followed when necessary by Kramer's (1956) multiple range test.

\section{Results}

\section{Histochemistry}

Positive evidence of the presence of hydrophobic neutral lipids in the uterine epithelial lipid droplets was given by the oil red $O$ staining. That these neutral lipids were almost entirely triacylglycerols was indicated by a positive result with the calcium lipase technique and negative results following the three other methods which demonstrate free fatty acids, cholesterol esters and free cholesterol.

\section{Lipid extraction}

There was good separation of the triacylglycerols from adjacent bands and thus minimal contamination in the silica gel removed for the elution of the lipids being investigated (Text-fig. 1). As well as the reference compounds, there were several other unidentified lipids extracted from the epithelial cells, e.g. on either side of the triacylglycerol band and well-developed bands preceding and following the cholesterol esters. The bands following the diglycerides were found in preliminary experiments to contain free fatty acids.

\section{Triacylglycerol assays}

The uterine epithelial triacylglycerols varied quantitatively with the reproductive state of the females (Table 1). Values at pro-oestrus were half those found during the remainder of the cycle.

During the preimplantation stages of pregnancy the triacylglycerol content decreased to low levels between Days 3 and 4, and these values were lower than that on the equivalent day of the oestrous cycle, dioestrus $(F=7.33$; d.f. 1,$8 ; 0.01<P<0.05)$. Values on Days 4 and 5 of pregnancy were comparable with those of pro-oestrus. The amounts of triacylglycerol present after treatment with medroxyprogesterone acetate were comparable with those of metoestrus, but treatment with oestradiol- $17 \beta$ resulted in very low levels. 


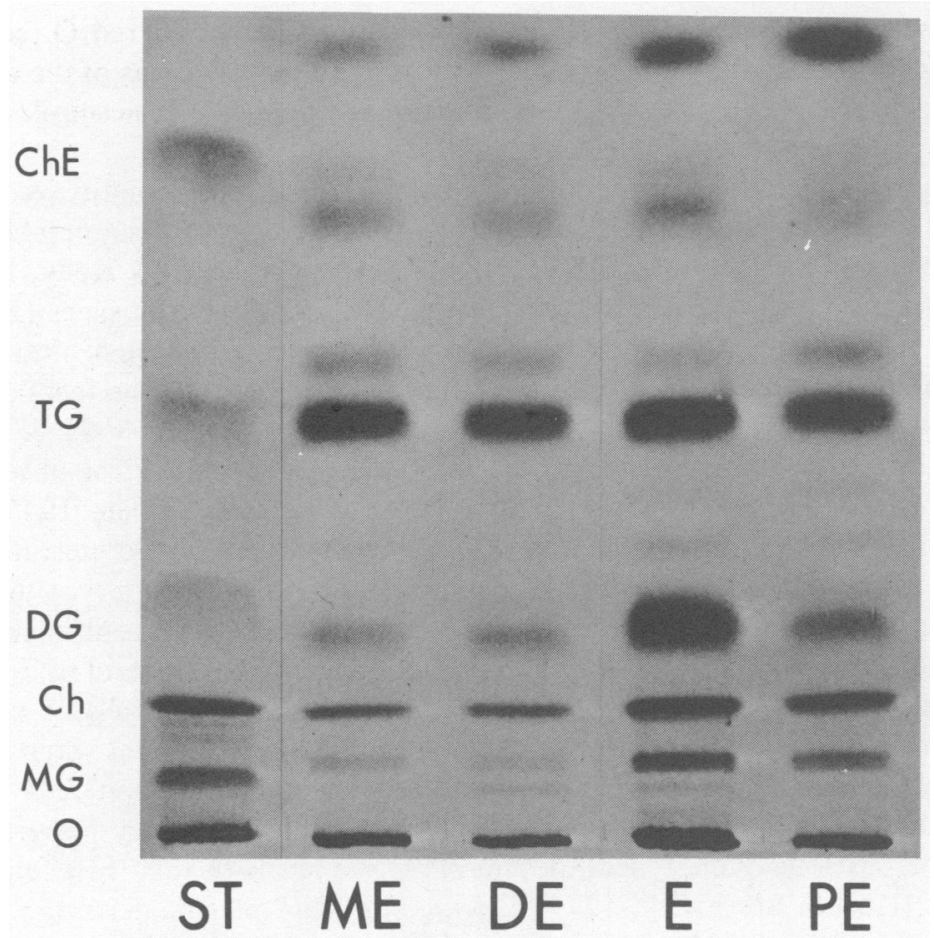

Text-fig. 1. Components of a typical thin-layer chromatography plate (Silica Gel G) showing separation of uterine epithelial lipids throughout the oestrous cycle (ME, metoestrus; DE, dioestrus; E, oestrus; PE, pro-oestrus) after their visualization with $\mathrm{I}_{2}$ vapour. The standard (ST) is represented from the origin $(\mathrm{O})$ by monoglyceride $(\mathrm{MG})$, cholesterol $(\mathrm{Ch})$, diglyceride (DG), triglyceride (TG) and cholesterol ester (ChE).

Table 1. Triacylglycerols in the uterine epithelium of rats in different reproductive states

\begin{tabular}{|c|c|c|c|c|c|c|c|c|c|}
\hline & \multicolumn{4}{|c|}{ Oestrous cycle } & \multicolumn{3}{|c|}{ Day of pregnancy } & \multicolumn{2}{|c|}{ Ovariectomized females } \\
\hline & $\begin{array}{l}\text { Pro-oestrus } \\
\text { (PE) }\end{array}$ & $\begin{array}{l}\text { Oestrus } \\
\text { (E) }\end{array}$ & $\begin{array}{l}\text { Metoestrus } \\
\text { (ME) }\end{array}$ & $\begin{array}{l}\text { Dioestrus } \\
\text { (DE) }\end{array}$ & $\begin{array}{l}\text { Day } 3 \\
\text { (D3) }\end{array}$ & $\begin{array}{l}\text { Day } 4 \\
\text { (D4) }\end{array}$ & $\begin{array}{l}\text { Day } 5 \\
\text { (D5) }\end{array}$ & $\begin{array}{c}\text { Oestradiol } \\
\left(E_{z}\right)\end{array}$ & MPA \\
\hline \multirow{5}{*}{$\begin{array}{l}\text { Triacylglycerol content } \\
\text { per assay* } \\
(\mu \mathrm{g} / \mu \mathrm{g} \text { DNA })\end{array}$} & 0.34 & 0.74 & 1.09 & 0.77 & $\begin{array}{l}0.45 \\
(6)\end{array}$ & $\begin{array}{c}0.22 \\
(6)\end{array}$ & $\begin{array}{c}0.14 \\
(6)\end{array}$ & 0.19 & 1.07 \\
\hline & 0.64 & 0.69 & 1.01 & 0.67 & $\begin{array}{c}0.41 \\
(5)\end{array}$ & $0 \cdot 30$ & $\begin{array}{c}0.32 \\
(3)\end{array}$ & $\begin{array}{l}0.11 \\
(3)\end{array}$ & 0.83 \\
\hline & 0.43 & 0.84 & 0.72 & 0.51 & $\begin{array}{c}0.61 \\
(3)\end{array}$ & $\begin{array}{c}0.28 \\
(3)\end{array}$ & 0.30 & 0.22 & 0.89 \\
\hline & 0.32 & 0.65 & 0.63 & 0.98 & 0.52 & $\begin{array}{c}0 \cdot 19 \\
(5)\end{array}$ & $\begin{array}{c}0.19 \\
(3)\end{array}$ & 0.19 & \\
\hline & 0.29 & & & $\begin{array}{l}0.70 \\
0.76\end{array}$ & & & & & \\
\hline \multirow{2}{*}{ Mean \pm s.d. } & 0.40 & 0.73 & 0.86 & 0.73 & 0.50 & 0.25 & 0.24 & 0.18 & 0.93 \\
\hline & \pm 0.14 & \pm 0.08 & \pm 0.22 & \pm 0.15 & \pm 0.09 & \pm 0.05 & \pm 0.09 & \pm 0.05 & $\pm 0 \cdot 13$ \\
\hline Total no. of females & 20 & 16 & 16 & 24 & 18 & 18 & 16 & 15 & 12 \\
\hline Analysis of variance & \multicolumn{4}{|c|}{$\mathrm{F}=7.35 ;$ d.f. 3,$15 ; P<0.05$} & \multicolumn{3}{|c|}{$\mathrm{F}=14.75 ;$ d.f. $2.9: P<0.01$} & \multicolumn{2}{|c|}{$\begin{array}{c}\mathrm{F}=127.76: \text { d.f. } 1.5: \\
P<0.01\end{array}$} \\
\hline Significance of results ${ }^{\dagger}$ & \multicolumn{4}{|c|}{$\mathrm{PE}<\mathrm{E} \leq \mathrm{DE}<\mathrm{ME}$} & \multicolumn{3}{|c|}{ D3 $>\underline{\text { D4 }>\text { D5 }}$} & \multicolumn{2}{|c|}{$\mathrm{E}_{2}<\mathrm{MPA}$} \\
\hline
\end{tabular}

* There were 4 females per assay except as otherwise indicated in parentheses.

+ Mean values for groups underlined are not different statistically at $P<0.05$ (Kramer. 1956).

\section{Discussion}

Utilization of specific methods for the histochemical analysis of neutral lipids (Bayliss High, 1977) demonstrated that the intracellular lipid droplets of the uterine epithelium were virtually 
entirely triacylglycerols: the lipid-containing vesicles stained by the oil red $\mathrm{O}$ technique and the calcium lipase technique for triglycerides were located in the same regions of the cells and were of comparable sizes. Only negligible amounts of free fatty acids, cholesterol esters and free cholesterol were present in the lipid droplets.

Previous studies of uterine biochemistry (see Manimekalai, Umpathy \& Govindarajulu, 1979) have used whole uteri or mixtures of many tissue types, but unless metabolic equivalence of the two major uterine tissue types has been demonstrated (see Abel \& Kelly, 1979), studies of whole uteri or tissue mixtures should not be extrapolated to individual tissues (Boshier \& Katz, 1975; Fagg \& Martin, 1979). The present study has demonstrated that triacylglycerol metabolism in the uterine epithelium reflects the reproductive state of the female, which itself is under the control of the ovarian hormones.

The low triacylglycerol content at pro-oestrus confirms histochemical observations which were relatively non-specific of the class of lipid being visualized (Alden, 1947; Hadjioloff \& Staneva, 1975). Biochemical studies have also shown that rodent whole uteri neutral lipids are low during pro-oestrus (Davis \& Alden, 1959; Goswami, Kar \& Chowdhury, 1963). The reduced triacylglycerols at pro-oestrus reflect the elevated esterase activity present in the epithelium at this time (Boshier \& Katz, 1975). Similarly, the effects of treatment of the ovariectomized females with oestradiol or a progestagen in lowering or raising the levels of uterine epithelial triacylglycerols, respectively, could also have been predicted from our 1975 study which showed that, whereas oestradiol increased epithelial esterase activity, MPA had no effect.

The plasma levels of oestradiol and progesterone are thus of primary importance, and their actions during the oestrous cycle reflect the uterine tissue levels of their respective cytoplasmic receptor proteins (Kurl \& Borthwick, 1979). During dioestrus, plasma oestradiol concentrations rise gradually to reach a peak at 09:00 h on the morning of pro-oestrus (Smith, Freeman \& Neill, 1975 ), thus facilitating esterase-mediated triacylglycerol hydrolysis, whereas plasma progesterone increases from 09:00 h on the morning of pro-oestrus and peaks $8 \mathrm{~h}$ after the oestradiol maximum. Consequently, the lipid storage-promoting role of progesterone is seen in the increased levels of triacylglycerols present on the morning of oestrus.

In early pregnancy similar endocrine controls appear to exist, because the rise in plasma oestradiol early on Day 3 of pregnancy (Watson, Anderson, Alam, O'Grady \& Heald, 1975) precedes the fall of epithelial triacylglycerols demonstrated here. This decline in epithelial neutral lipids during early pregnancy is contrary to other reports which suggested their increase at this time. However, the histochemical studies (Alden, 1947; Hall, 1975) were not of the required specificity (Bayliss High, 1977) and the biochemical studies (Beall \& Werthessen, 1971) did not distinguish between the endometrial and myometrial components.

Although functional correlations of these changes in epithelial triacylglycerol content must be conjectural, the period pro-oestrus-oestrus is one of great endometrial activity in laboratory rodents, and it is also the period of greatest biosynthetic ability for the production of prostaglandins E and F (Desouza, Jain, Verma \& Garg, 1979). Arachidonic acid, a prostaglandin precursor, is a component of the rat uterine epithelial triacylglycerols (D. $P$. Boshier \& M. Robertson, unpublished data). Increased cellularity and synthetic activity in the rat uterus and blastocysts during the preimplantation period have also been demonstrated (Mohla, Prasad \& Dass, 1970). These and other observations (Boshier, 1976; Kennedy, 1977) suggest that the epithelial triacylglycerols would be a suitable and readily available energy and metabolite source for use by the uterus and blastocysts at these times.

This work was supported by the Medical Research Council of New Zealand. We thank Mr I. R. MacDonald for help with the photographs and Miss J. M. Westbrooke for help in the preparation of the manuscript. 


\section{References}

Abel, M.H. \& Kelly, R.W. (1979) Differential production of prostaglandins within the human uterus. Prostaglandins 18, 821-828.

Alden, R.H. (1947) Implantation of the rat egg. II. Alterations in osmiophilic epithelial lipids of the rat uterus under normal and experimental conditions. Anat. Rec. 97, 1-19.

Bayliss High, O. (1977) Lipids. In Theory and Practice of Histological Techniques, pp. 168-185. Eds J. D. Bancroft \& A. Stevens. Churchill Livingstone, London.

Beall, J.R. \& Werthessen, N.T. (1971) Lipid metabolism of the rat uterus after mating. $J$. Endocr. 51, $637-644$.

Bojesen, I. (1974) Quantitative and qualitative analyses of isolated lipid droplets from interstitial cells in renal papillae from various species. Lipids 9, 835-843.

Boshier, D.P. (1976) Effects of the rat blastocyst on neutral lipids and non-specific esterases in the uterine luminal epithelium at the implantation area. $J$. Reprod. Fert. 46, 245-247.

Boshier, D.P. \& Holloway, H. (1973) Effects of ovarian steroid hormones on histochemically demonstrable lipids in the rat uterine epithelium. J. Endocr. 56, 59-67.

Boshier, D.P. \& Katz, J.M. (1975) Effects of ovarian steroid hormones on esterases in the endometrium. $J$. Endocr. 64, 465-474.

Boshier, D.P. \& Millener, N.M. (1980) Ovarian hormones and rat uterine epithelial triacylglycerols. Proc. 6th Int. Cong. Endocr., Melbourne, p. 615, Abstr. 812.

Burton, K. (1956) A study of the conditions and mechanism of the diphenylamine reaction for the colorimetric estimation of deoxyribonucleic acid. Biochem. J. 62, 315-323.

Davis, J.S. \& Alden, R.H. (1959) Hormonal influence on lipid metabolism of rat uterus. Anat. Rec. 134, 725-737.

Desouza, A.N., Jain, V.K., Verma, O.P. \& Garg, S.K. (1979) Prostaglandins $E$ and $F$ in the uterine tissue of cyclic rats. Int. J. Fert. 24, 130-133.

Fagg, B. \& Martin, L. (1979) Oestrogen content of the uterine tissues of mice and their relationship to epithelial cell proliferation after subcutaneous and intraluminal administration of hormones. J. Endocr. 83, 295-302.

Folch, J., Lees, M. \& Sloane Stanley, G.H. (1957) A simple method for the isolation and purification of total lipids from animal tissues. J. biol. Chem. 226, 497-509.
Galetti, F. (1967) An improved colorimetric micromethod for the determination of serum glycerides. Clin. Chim. Acta 15, 184-186.

Goswami, A., Kar, A.B. \& Chowdhury, S.R. (1963) Uterine lipid metabolism in mice during the oestrous cycle: effect of ovariectomy and replacement therapy. J. Reprod. Fert. 6, 287-295.

Hadjioloff, A.J. \& Staneva, L.L. (1975) The histochemistry of the lipids in the rat uterus after ovariectomy and after treatment with oestrogen. $C$. R. Acad. Bulg. Sci. 28, 423-425.

Hall, K. (1975) Lipids in the mouse uterus during early pregnancy. J. Endocr. 65, 233-243.

Hojnacki, J.L. \& Smith, S.C. (1974) Separation of six lipid classes on one thin-layer chromatogram. $J$. Chromat. 90, 365-36\%.

Kennedy, T.G. (1977) Evidence for a role for prostaglandins in the initiation of blastocyst implantation in the rat. Biol. Reprod. 16, 286-291.

Kennedy, T.G. \& Zamecnik, J. (1978) The concentration of 6-keto-prostaglandin $F_{I_{\alpha}}$ is markedly elevated at the site of blastocyst implantation in the rat. Prostaglandins 16, 599-605.

Kramer, C.Y. (1956) Extension of multiple range tests to groups means with unequal nembers of replications. Biometrics 12, 307-310.

Kurl, R.N. \& Borthwick, N.M. (1979) Progesterone receptors and RNA polymerase activity in the rat uterus during the oestrous cycle. J. Endocr. 83, 41-51.

Manimekalai, S., Umpathy, E. \& Govindarajulu, P. (1979) Hormonal influence on uterine lipids. Hormone Res. 10, 213-221.

Mohla, S., Prasad, M.R.N. \& Dass, C.M.S. (1970) Nucleic acid and protein synthesis in the blastocyst and uterus during early pregnancy in the rat. Endocrinology 87, 383-393.

Nissen, H.M. \& Bojesen, 1.N. (1969) On lipid droplets in renal interstitial cells. IV. Isolation and identification. Z. Zellforsch. Mikrosk. Anat. 97, 274-284.

Smith, M.S., Freeman, M.E. \& Neill, J.D. (1975) The control of progesterone secretion during the estrous cycle and early pseudopregnancy in the rat: prolactin, gonadotropin and steroid levels associated with rescue of the corpus luteum of pseudopregnancy. Endocrinology 96, 219-226.

Watson, J., Anderson, F.B., Alam, M., O'Grady, J.E. \& Heald, P.J. (1975) Plasma hormones and pituitary luteinizing hormone in the rat during the early stages of pregnancy and after post-coital treatment with tamoxifen (ICI 46,474). J. Endocr. 65, 7-17.

Received 16 September 1980 